\title{
Analysis of Void Growth and Coalescence in Porous Polymer Materials
}

\author{
Coalescence in Polymer Materials
}

\author{
Sid Ahmed Reffas \\ Djillali Liabes University of Sidi Bel \\ Abbes, Algeria \\ reffas_ahmed@yahoo.fr
}

\author{
Mohamed Elmeguenni \\ Djillali Liabes University of Sidi Bel \\ Abbes, Algeria \\ elmeguennimohamed@yahoo.fr
}

\author{
Mohamed Benguediab \\ Djillali Liabes University of Sidi Bel \\ Abbes, Algeria \\ benguediab_m@yahoo.fr
}

\begin{abstract}
The use of polymeric materials in engineering applications is growing more and more all over the world. This issue requests new methodologies of analysis in order to assess the material's capability to withstand complex loads. The use of polyacetal in engineering applications has increased rapidly in the last decade. In order to evaluate the behavior, the damage and coalescence of this type of polymer, a numerical method based on damage which occurs following several stages (nucleation of cavities, their growth and coalescence in more advanced stages of deformation) is proposed in this work. A particular attention is given on the stress-strain and the volumetric strain evolution under different triaxiality and for three initial void shapes. Its application to polyacetal allows approving this approach for technical polymers. Finally, this method allow us to compare the obtained results of basic calculations at different triaxiality and to discuss their possible influence on the initial size and the geometrical shape of the porosity on the material failure.
\end{abstract}

Keywords- void growth; Coalescence; representative elementary volume( RVE); ductile; Polyoxymethylene (POM); acetal

\section{INTRODUCTION}

In the plastics industry, technical polymers are widely used in engineering components which may experience complex mechanical loadings. The understanding of their intrinsic mechanical behavior to evaluate the mechanisms of damage and coalescence, is of prime importance in order to make better choices in the design of all components. Over recent years, considerable attention has been focused on the analysis of plastic deformation of the ductile materials and solid polymers. The deformation processes involved in the plastic deformation of the ductile materials have been widely investigated by several authors [1-19], however, most studies conducted on solid polymers are based on the same criteria. Phenomenological laws have been proposed by some researchers [20-25] and other studies have been based only on the mechanical behavior of polymers in large scale deformation [26-36]. Research efforts have been devoted to understanding the mechanisms of voids growth and coalescence and to developing micro-mechanical models for better describing the ductile fracture of polymers. Probably the best-known expansion plasticity model is the one introduced by Gurson [20], later modified by Tvergaard and Needleman [37-39].

The Gurson model was derived based on the assumption that the deformation mode of the matrix material surrounding a void is homogenous. It can therefore predict the material softening behavior due to the nucleation and growth of voids, but has no intrinsic ability to predict the shift of a homogenous deformation mode to a localized mode by void coalescence.

For our work, the representative elementary volume (RVE) method has been chosen, where the stress depends on the deformation, the strain rate and the stress triaxiality effect. This law has been used successful to characterize the behavior of a great number of polymers with an empirical criterion, like the critical void volume fraction.

In this study, a numerical simulation on the basis of the model of an elementary cell is presented. Firstly, the unit cell model which is used to predict the response of a material consisting of a periodic assembly of RVE is briefly described. Secondly, a method developed for the calculation of cells while maintaining a constant triaxiality during the loading is described. This method allows us to compare results of basic calculations for all triaxiality used in this study and to summarize the effects of the various geometrical parameters on the void coalescence in the acetal material (Polyoxymethylene or POM). Finally, the relevant features which should be taken into account in the application of an accurate constitutive RVE model are discussed with a particular attention paid on volumetric strain, damage and their evolutions for all triaxiality.

\section{MATERIAL AND NUMERICAL PROCEDURE}

The void matrix material is characterized by a model type of material (POM). The yield stress of the virgin matrix material $\sigma_{0}$ is set to be $55 \mathrm{MPa}$. The elastic properties of the model material are taken as $E=2900 \mathrm{MPa}$ and $v=0.4$. The results obtained using the standard tensile tests are presented in Figure 1. The objective of these tests is to demonstrate the strain-rate effect on the response and fracture under large deformation of the POM material. Tests were conducted on an 
INSTRON machine. An optical measurement system was used to control the strain-rate and measure the local strain in the specimen section. The mechanical tests were achieved at thre strain rates of $10^{-1}, 10^{-2}$ and $10^{-3}$ at room temperature $\left(23^{\circ} \mathrm{C}\right)$.

The POM material exhibits an influence of strain rate on the nonlinear behavior. In order to observe this effect, and to quantify it, an overview of the strain-rate effect on the true stress-strain curves is firstly analyzed.

Figure 1 indicates that the response of this material is similar to other polymers seen in the literature on the viscoelastic evolution. However, the overall response looks like ductile materials. In this response, the curve shows a proportional limit followed by a maximum at which necking takes place. It is common to term this maximum as the yield stress in polymer materials.

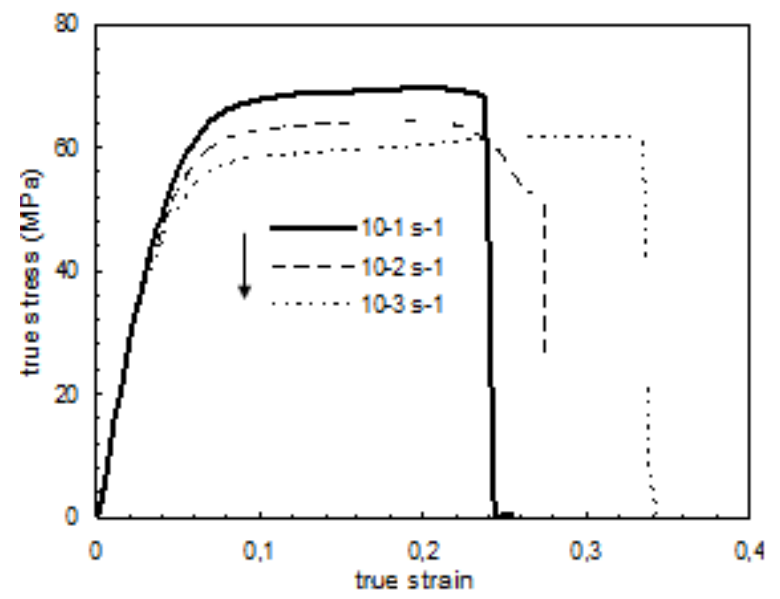

Fig. 1. Experimental true stress - strain curves during POM at $23^{\circ} \mathrm{C}(10-1$ $\mathrm{s}-1 ; 10-2 \mathrm{~s}-2$ and $10-3 \mathrm{~s}-3)$.
After experimental testing, results show that the behavior of the POM has the same evolution with ductile materials. So, for a first approach, a law already used for metals is applied. The objective is to verify the relevance of this law to this type of polymer. In the present work, the rate-independent power law strain hardening material is applied. The flow stress of the virgin matrix material is described as:

$$
\sigma_{f}=\sigma_{0}\left(1+\frac{\varepsilon_{p}}{\varepsilon_{0}}\right)^{n}
$$

Where $\sigma_{f}$ is the flow stress, $\varepsilon_{p}$ the equivalent plastic strain, $\sigma_{0}$ the yield stress, $\varepsilon_{0}=\sigma_{0} / E$ the yield strain, and $n$ the plastic strain hardening exponent. Three moderate hardening exponents $n$ have been used to verify a good relationship and representation with the experimental curve $(n=0.01,0.05$ and $0.08)$.

In the idea of good representation, two pre-strain cases have been considered $(1.5 \%$ and $2.5 \%)$. The pre-strain here means the permanent strain after unloading. Pre-strain induces strain hardening and residual stress in the void model as well as void growth and void shape changes. In order to separate the strain hardening effect from the one due to void shape changes, ellipsoidal, and spherical voids with a void volume faction equivalent to the one at the end of pre-strain history and a homogenous pre-strained matrix material have been analyzed.

Figure 2 compares the virgin material with the three moderate hardening exponents in $(a)$ and the two homogenous pre-strained matrix materials in $(b)$. It should be noted that in this study, $n=0.05$ and $1.5 \%$ of pre-strain have been chosen. The stress-strain curve of the material shown in Figure 2 is obtained by trimming the virgin material curve by the specified pre-strain level. The elastic properties of the pre-strained materials are kept identical to the virgin material.
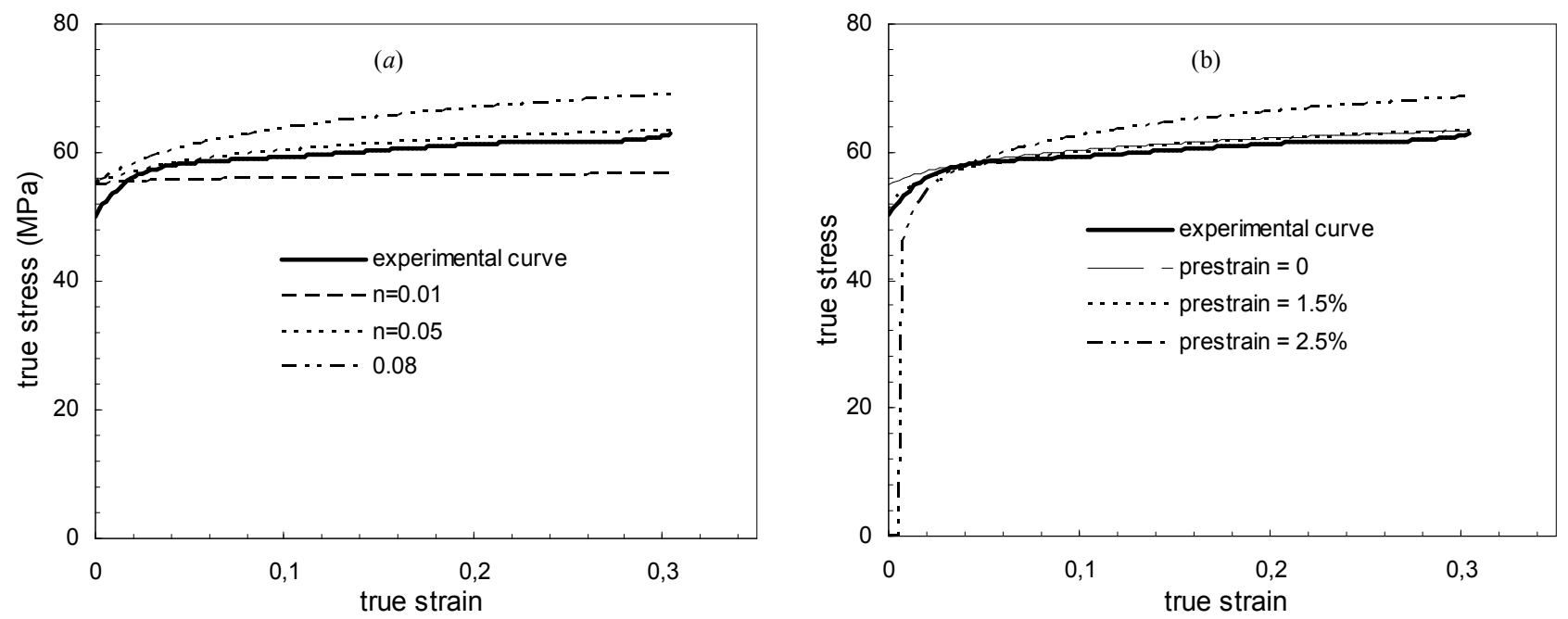

Fig. 2. Matrix material properties used in the analyses: $a$ ) The plastic strain hardening exponent (n); $b$ ) The pre-strain variability for the virgin material 
Figure 3 shows the quarter unit cell model used in the study. The model has been used previously for various studies on the void coalescence behavior [40-46]. The model is axisymmetric and the stress ratios $\rho=\Sigma_{x} / \Sigma_{y}$ are kept constant in both the pre-straining analysis and subsequent analyses. The model was analysed in a load-controlled manner and ABAQUS-RIKS method has been applied [47]. Nodal constraints were applied such that the left and top boundaries remain vertical and horizontal during the analysis.

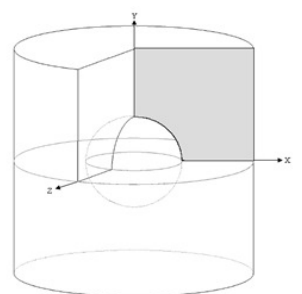

(a)

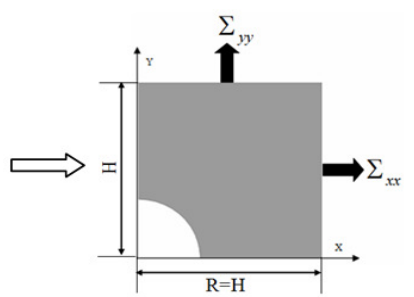

(b)
Fig.3. A voided unit cell model and the region analyzed numerically: $a$ ) a voided unit cell model and; $b$ ) one quarter of the unit cell model.
For the axisymmetric problem considered the stress triaxiality can be calculated from the stress ratio $\alpha$ :

$$
\beta=\frac{\sigma_{h}}{\sigma_{e q}}=\frac{1+2 \alpha}{3(1-\alpha)}
$$

where $\sigma_{h}$ is the hydrostatic stress and $\sigma_{e q}$ the von Mises equivalent stress.

The initial radius and height of the model are denoted as $L_{x 0}, L_{y 0}, R_{y 0}$ and $R_{z 0}$ and represent the initial radii of the void. The results are based mainly on the case with an initial void volume fraction of $1 \%$. Voids with different initial shapes (spherical, prolate, and oblate) but same initial void volume fraction are also considered (Figure 4). The initial and current void aspect ratios are defined as:

$$
\left\{\begin{array}{l}
S_{0}=\frac{R_{z 0}}{R_{y 0}} \\
S=\frac{R_{y}}{R_{z}}
\end{array}\right.
$$

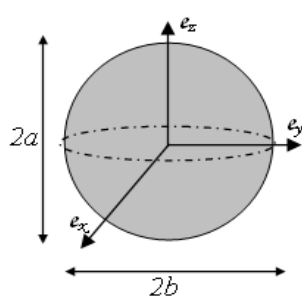

(a)

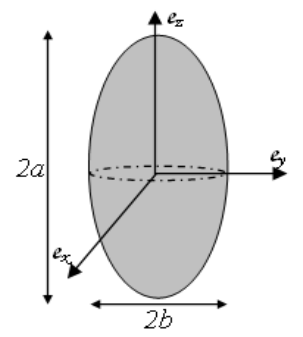

(b)

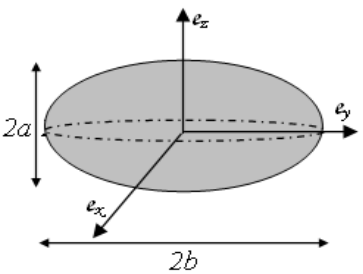

(c)

Fig. 4. Three initial void shapes considered in the study: $a$ ) spherical void with $\mathrm{S}=1 ; b$ ) prolate void with $\mathrm{S}=4 ; c$ ) oblate void with $\mathrm{S}=0.25$.

The microscopic strain and Cauchy stress tensors inside the matrix are denoted by small letters $\varepsilon$ and $\sigma$, whereas the macroscopic strain and stress tensors are denoted by the capital letters $E$ and $\Sigma$. The overall deformation of the cell model can be calculated from the normal displacements of the outer faces. Because of the symmetry of the problem on hand, the macroscopic total logarithmic strain tensor $E$ and Cauchy stresses tensor $\Sigma$ possess the same principal directions, which are the radial and axial directions. The tensor $E$ is qualitatively given by:

$$
E=E_{p}\left(\underline{e}_{y} \otimes \underline{e}_{y}+\underline{e}_{x} \otimes \underline{e}_{x}\right)+\mathrm{E}_{z} \underline{e}_{z} \otimes \underline{e}_{z}
$$

The Macroscopic asymmetric radial $\left(E_{1}\right)$ and axial $\left(E_{2}\right)$ deformations are defined by the following expressions:

$$
\left\{\begin{array}{l}
E_{1}=\ln \left(1+\frac{u_{1}^{A}}{L_{y 0}}\right) \\
E_{2}=\ln \left(1+\frac{u_{2}^{A}}{L_{z 0}}\right)
\end{array}\right.
$$

For the purpose of specifying the overall plastic deformation of the cell model, we choose the effective strain $E_{e}$ defined by:

$$
E_{e}=\frac{2}{3}\left|E_{2}-E_{1}\right|
$$

as an independent variable for presenting most results. The macroscopic stress tensor $\Sigma$ is qualitatively given by:

$$
\Sigma=\Sigma_{p}\left(\underline{e}_{y} \otimes \underline{e}_{y}+\underline{e}_{x} \otimes \underline{e}_{x}\right)+\Sigma_{z} \underline{e}_{z} \otimes \underline{e}_{z}
$$

With the remote true principal stresses $\Sigma_{y}$ in both $y$ and $x$ directions, and $\Sigma_{z}$ in $z$-one. They are calculated at any instant as the average reaction forces at the cell faces per momentary areas through.

$$
\left\{\begin{array}{l}
\Sigma_{y}=\frac{1}{L_{z}} \int_{0}^{L_{z}} T_{y} d z \\
\Sigma_{z}=\frac{2}{L_{y}^{2}} \int_{0}^{L} y T_{z=L y} d y
\end{array}\right.
$$


where $T$ is the stress vector. The corresponding effective von Mises stress $\Sigma_{e}$ and hydrostatic stress $\Sigma_{h}$ result from:

$$
\left\{\begin{array}{l}
\Sigma_{e}=\left|\Sigma_{z}-\Sigma_{y}\right| \\
\Sigma_{h}=\frac{1}{3}\left(\Sigma_{z}+2 \Sigma_{y}\right)
\end{array}\right.
$$

and the overall stress triaxiality $\beta$ of the stress state is defined as the ratio:

$$
\begin{gathered}
\beta=\frac{\Sigma_{h}}{\Sigma_{e}}=\frac{1}{3}\left(\frac{\Sigma_{z}+2 \Sigma_{y}}{\left|\Sigma_{z}-\Sigma_{y}\right|}\right)=\frac{1}{3}\left(\frac{1+2 \alpha}{|1-\alpha|}\right) \\
\text { with } \quad \alpha=\frac{\Sigma_{y}}{\Sigma_{z}}
\end{gathered}
$$

The stress triaxiality equals $1 / 3$ (or $\alpha=0$ ) for simple uniaxial tension and 0 (or $\alpha=-0.5$ ) for pure shear. Figure 5 shows the evolution of stress ratio $\alpha$ versus the triaxiality $\beta$ used in the study.

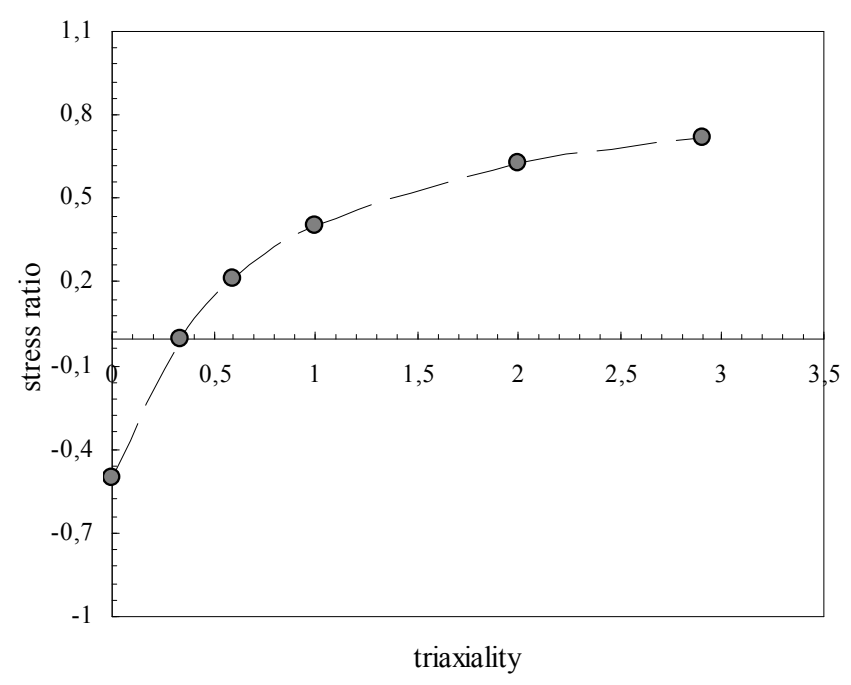

Fig.5. Evolution of stress ratio versus the triaxiality.

\section{METHOD OF ANALYSIS}

In as much as the unit cell is subjected to axisymmetric deformation, the analysis of its evolution is performed using a cylindrical coordinate system with an orthonormal frame denoted by $\left(e_{x}, e_{y}, e_{z}\right)$ along $y$-radial, $x$-ortho-radial and $z$-axial axis. In the initial undeformed configuration, the unit cell is a cylinder with diameter $2 L_{Y 0}$ and height $2 L_{Z 0}$. The voids are assumed to be spheroidal initially with radius $R_{Y 0}$ and half length $R_{Z 0}$. The void is oblate if $R_{Y 0}>R_{Z 0}$, and prolate if $R_{Y 0}<$ $R_{Z 0}$.

The particular case of a spherical void with radius $R_{y 0}$ corresponds to the situation for which $R_{Y 0}=R_{Z 0}$. The void volume fraction $f$ is defined as the ratio of the total void volume to the unit cell volume. The void volume fraction can be calculated in two ways: the first is by numerical integration of the points along the surface of the void volume; a second criterion is by using the approximate formula proposed by Koplik and Needleman [41]. This relationship has been proposed assuming the matrix plastically incompressible.

The initial cell geometry is completely characterized by the void volume fraction, the void aspect ratio and the cell aspect ratio which their initial values, $f_{0}, S_{0}$ and $\lambda_{0}$ are respectively defined by:

$$
\begin{gathered}
f_{0}=\frac{2}{3}\left(\frac{R_{y 0}}{L_{y 0}}\right)^{2}\left(\frac{R_{z 0}}{L_{z 0}}\right) \\
\lambda_{0}=\frac{L_{z 0}}{L_{y 0}}
\end{gathered}
$$

As a consequence of the lattice periodicity, all outer planes of the unit cell have to behave only as rigid moveable planes in coordinating directions during the process of loading. The faces at $y=L_{y o}$ and $z=L_{z o}$ will have a uniform normal displacements and their mutual orientations will be maintained. These requirements impose the unit cell to remain a cylinder during the finite strain deformation process. This feature is attained by assessing the deformation via an imposed homogeneous elongation $\left(u_{z}^{A}\right)$ of the corner $A$ in the axial direction and monitoring its homogeneous radial displacement $\left(u_{y}{ }^{A}\right)$ by multipoint constraints. The cylinder is thus characterized in an arbitrary state by:

$$
\left\{\begin{array}{l}
L_{y}=L_{y 0}+u_{y}^{A} \\
L_{z}=L_{z 0}+u_{z}^{A}
\end{array}\right.
$$

Because of these constraints, only one quarter geometry of the unit cell model $\left(0 \leq y \leq L_{y o} ; 0 \leq z \leq L_{z o}\right)$ needs to be analyzed and is drawn in Figure 3-b. To satisfy the axisymmetric conditions and to ensure periodicity of the cell arrangements, the boundary conditions of the quadrant dealing with displacements read, $u_{y}=0$ along the axis, $u_{z}=0$ on the bottom and $u_{y}=u_{y}{ }^{A}$ on the lateral surface, $u_{z}=u_{z}^{A}$ on the top.

The actual void volume fraction $f$ is calculated whether using numerical integration from the updated coordinates of the nodes at the void-matrix interface during the deformation of the unit cell, or using the following approximate analytic formula proposed in (8).

$$
f=1-\frac{V_{0}}{V}\left(1-f_{0}\right)-\frac{\Delta V^{e}}{V}
$$

$$
\text { with } \frac{\Delta V^{e}}{V}=\left(1-f_{0}\right) \frac{3(1-v)}{E} \Sigma_{h}
$$

where the ratio of the current volume $V$ of the unit cell to its initial volume $V_{0}$ is given by:

$$
\frac{V}{V_{0}}=\frac{\left(L_{y 0}+u_{y}^{A}\right)^{2}\left(L_{z 0}+u_{z}^{A}\right)}{L_{y 0}^{2} L_{z 0}}
$$


$\Delta V^{e}$ is an approximate correction term for the elastic expansion change in cell volume due to the imposed hydrostatic stress $\Sigma_{h}$. It was checked that the two methods yield very close results within the range of our calculations. It should be mentioned however, that (16) does not hold in the case of porous matrix. On the other hand, it should be kept in mind that this approximation will be used in the transient analysis of the cell model to provide the starting loading for which, as will be seen later, it turns out that the stress triaxiality drops down quickly and then have to be corrected.

\section{NUMERICAL RESULTS AND DISCUSSION}

In order to evaluate the proposed transient analysis for axisymmetric cell model simulations, a series of calculations have been conducted. Figure 6 shows the mesoscopic radial strain versus equivalent strain curves for the case with an initial void volume fraction of $1 \%$ and for all triaxiality proposed in this study from 0.33 to 3 .

A global view of these results indicates that there is rather a reasonably good agreement between the results. However, it is seen from these curves that a difference exists in the nature of the response especially in the coalescence. In general, the cell model elongates in the vertical direction and contracts in the radial direction. During the plastic deformation and void growth, an approximate linear relation can be observed. This linear relation indicates a homogenous deformed state. When the deformation reaches a critical state a sudden shift from the relatively homogenous deformation state to a uniaxial straining state can be seen. This shift depicts the onset of void coalescence. Computations were carried out for all cell models, whereby the extreme values of stress triaxialty from 0.33 to 3 were investigated. The most interesting outcome of the cell models is the overall mesoscopic hardening and failure behavior. This relation is expressed in term of the invariants of the equivalent stress versus equivalent strain.

Figure 7(a) displays variations of the equivalent stress as a function of the equivalent strain. The onset of void coalescence corresponds to a marked change of the slope of the curves. The transition is most sharp at low stress triaxiality, where the triaxiality effect is marked. It has all also been shown that after the onset of void coalescence the falling equivalent stressstrain curves is nearly linear, except for the high triaxiality (2 and 3).

Figure 7(b) exhibits the variations of the volumetric strain as a function of the equivalent strain. Void coalescence induces an increase in the void growth rate and a transition in the void shape evolution. After the onset of void coalescence, the volumetric strain growth is significantly larger. The end of the coalescence process in a polymer material usually consists of the failure of the remaining ligament by microcleavage, crystallographic shearing, or with the help of the second population of smaller voids, rather than volumetric void growth until impingement.

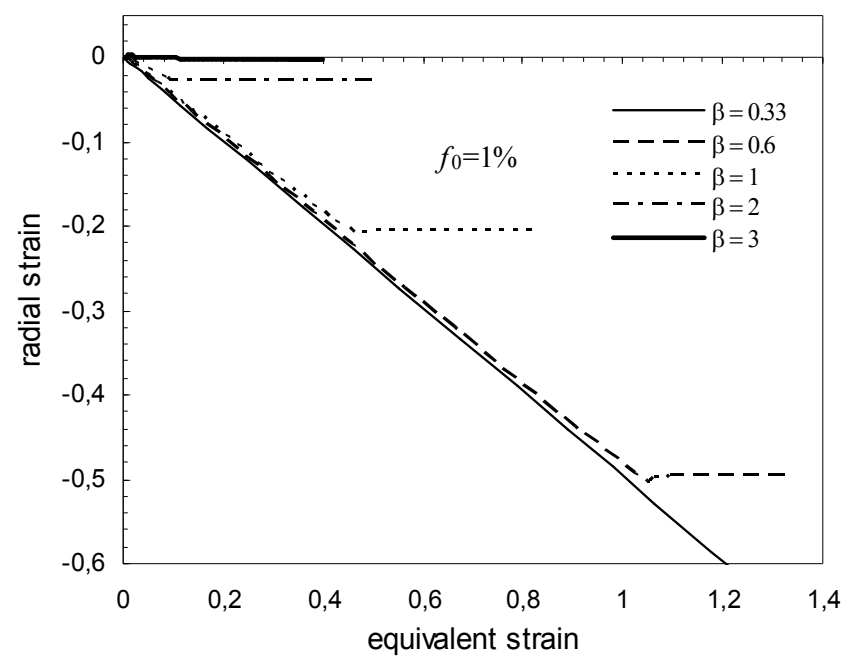

Fig. 6. Radial strain versus equivalent strain for different stress triaxiality.
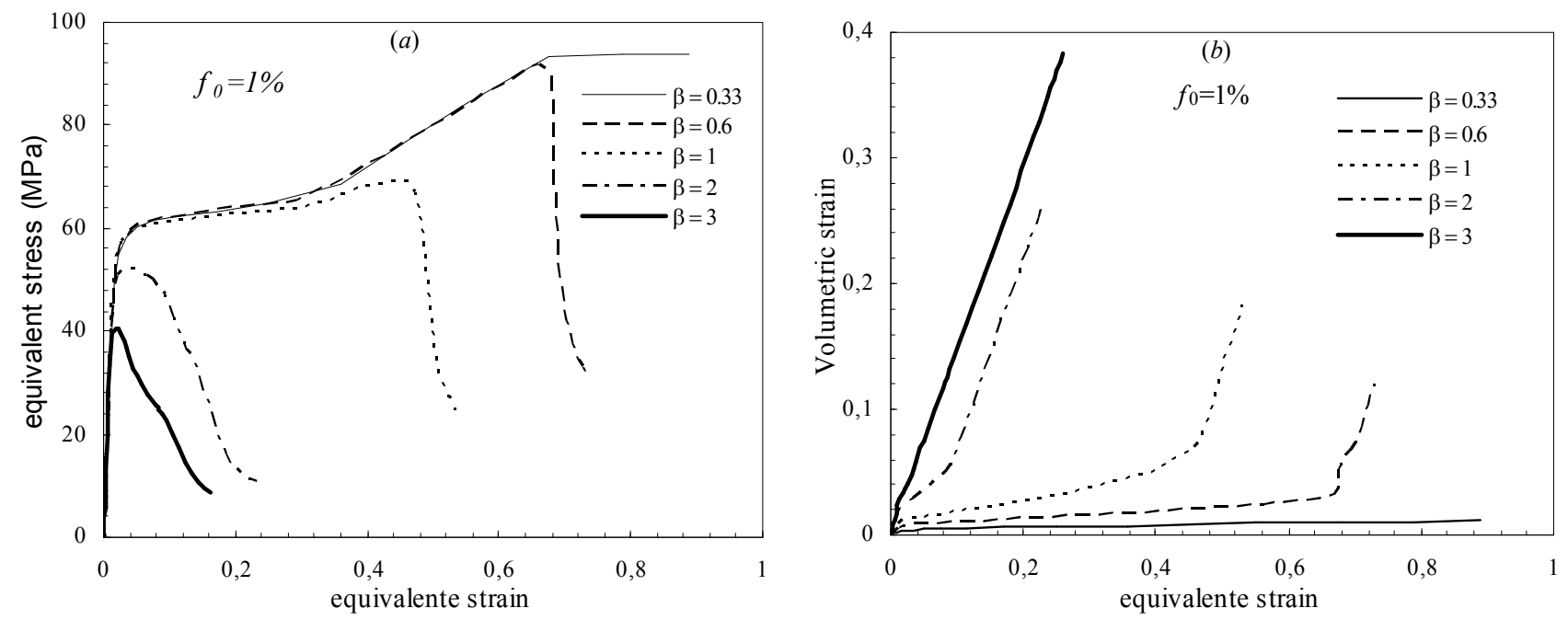

Fig.7. Cell model results for spherical void in different stress triaxiality: $a$ ) Equivalent stress versus equivalent strain; $b$ ) Volumetric strain versus equivalent strain 
In the previous results we note a reduction of the void diameter which depends on the triaxiality occurred in the course of loading. To study the influence of this additional condition on the mechanical behavior of the cell, we have chosen three cases of void volume fraction $(1 \%, 5 \%$ and $10 \%)$ with different initial shapes (spherical, prolate, and oblate) (Figure 4). Computations were carried out for all cell models, whereby the extreme values of stress triaxialty from 0.33 to 3 is investigated.

Figure 8 shows the evolution of the mesoscopic equivalent stress versus equivalent strain curves and summarizes the effects of the various geometrical parameters on void coalescence; the three cases of void volume fraction $(1 \%, 5 \%$ and $10 \%$ ) with different initial shapes (spherical, prolate, and oblate) for all triaxiality. Here the equivalent stress and strain are chosen, because both are relevant coalescence parameters. All the cells were loaded with a prescribed triaxiality $\beta=0.33$ to 3.

Several comments can be made concerning the void coalescence. The onset of void coalescence depends strongly on the relative void spacing as can be discerned by comparing cells $(1 \%$ spherical with $\beta=0.33)$ and $(1 \%$ spherical with $\beta=3)$, which have an identical void shapes and initial porosity. The effect can be seen in another way by comparing cells $(5 \%$ or $10 \%$ prolate) and (5\% or $10 \%$ oblate) for all triaxiality, which has been chosen with roughly similar void spacing. The cells have not a similar coalescence strain for the same initial void volume fractions and different shapes. The conclusion to be drawn is that heterogeneity in the void distribution inherited from prior working or processing plays a major role in the coalescence of the material.

Void spacing is not the only influential parameter as can be seen when comparing figure 9-a and figure 9-e (spherical; 5\% and $10 \%$ prolate or oblate). In these comparisons, a higher level of triaxiality builds up in the ligament of cell and accelerating localization of the coalescence.

For a similar cell aspect ratio, cells ( $10 \%$ prolate) and (10\% oblate) also have significant differences between the slopes after the onset of void coalescence, due to the differing initial porosity and void shape.
The analysis of the stress and strain fields inside several void cells has shown that voids start interacting with each other well before the onset of void coalescence. Figure 9 compares the critical stress and strain obtained at the moment of the coalescence as a function of the triaxiality for the different geometrical parameters on void coalescence in all cases. In general, stress triaxiality has a negative effect on the coalescence stress and strain. It is interesting to observe that both the void shapes have a strong influence on the reduction of the coalescence stress and strain.

\section{CONCLUSION}

In order to summarize the observed results in this paper, and to confirm predictions of the RVE model, we have noted some conclusions.

When the peak equivalent stress - strain appears at the outer boundary; the void coalescence starts. The microscopic coalescence criterion is practical and has been applied to determine the coalescence. However, this observation further verifies the plastic limit load theory for void coalescence, and the void coalescence occurs when a plastic limit load state of the void cell model has been reached.

The void coalescence behavior effect is strongly dependent on the stress triaxiality and the initial void shape. For prolate and oblate voids smaller than $5 \%$, the critical stress and the strain coalescence effect can be neglected. At high stress triaxiality cases the reduction in coalescence stress - strain due to the initial voids higher than $5 \%$ can be very significant. For an initially spherical void with $\beta=3$, the reduction in coalescence strain can be as large as $70 \%$. In comparison, the stress triaxiality effect of the coalescence strain of oblate voids is the largest. The absolute reduction of coalescence strain seems to be dependent of stress triaxiality.

Finally, it can be noted that the predictions show promising results, and these calculations show that the constitutive equations for damage evolution are required, and the determination of onset and continuation of a triaxiality is based on the initial porosity shape. 

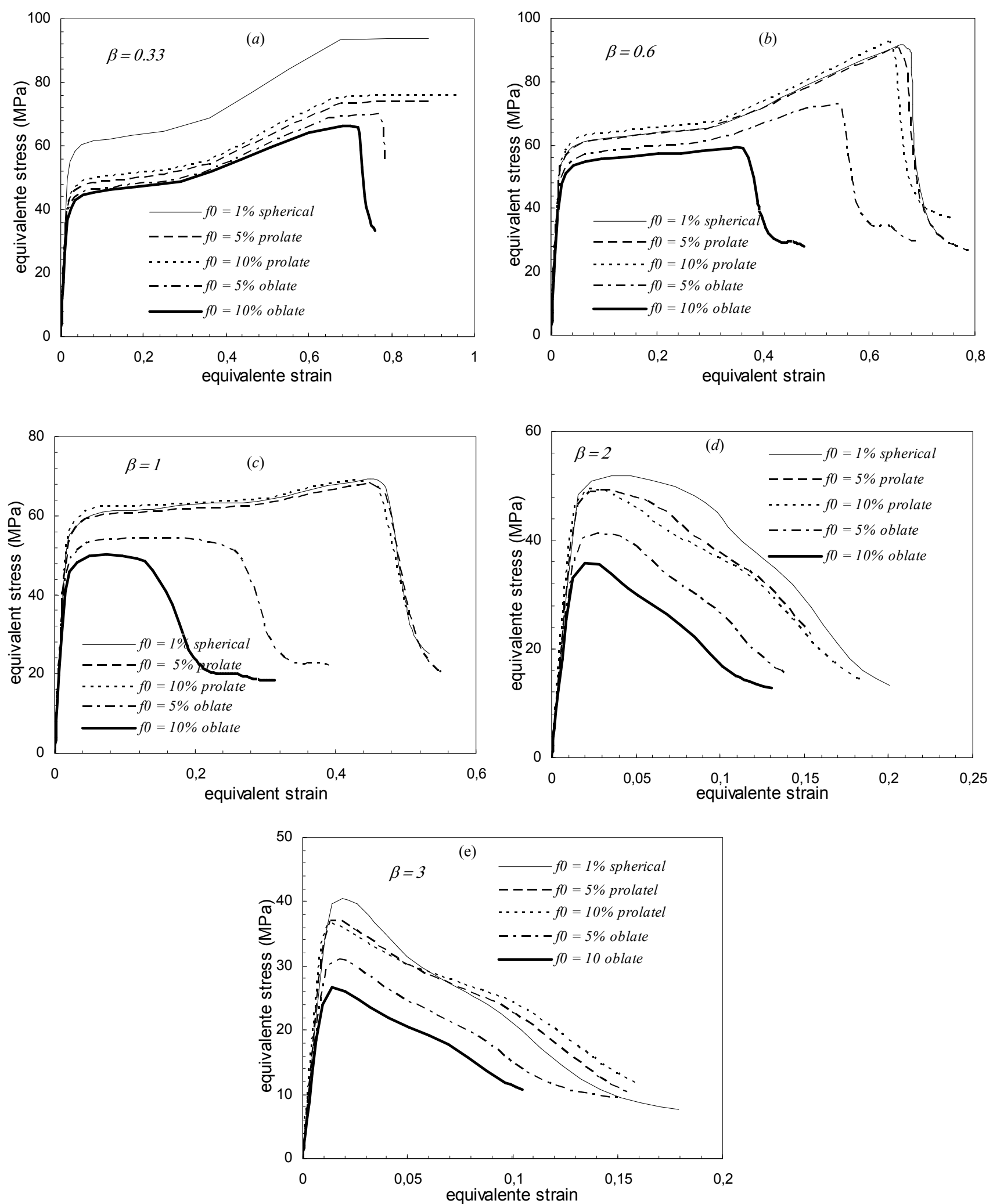

Fig. 8. Cell model results for three initial void shapes (spherical; prolate and oblate): (a) $\beta=0.33 ;(b) \beta=0.6 ;(c) \beta=1 ;(d) \beta=2 ;(e) \beta=3$. 

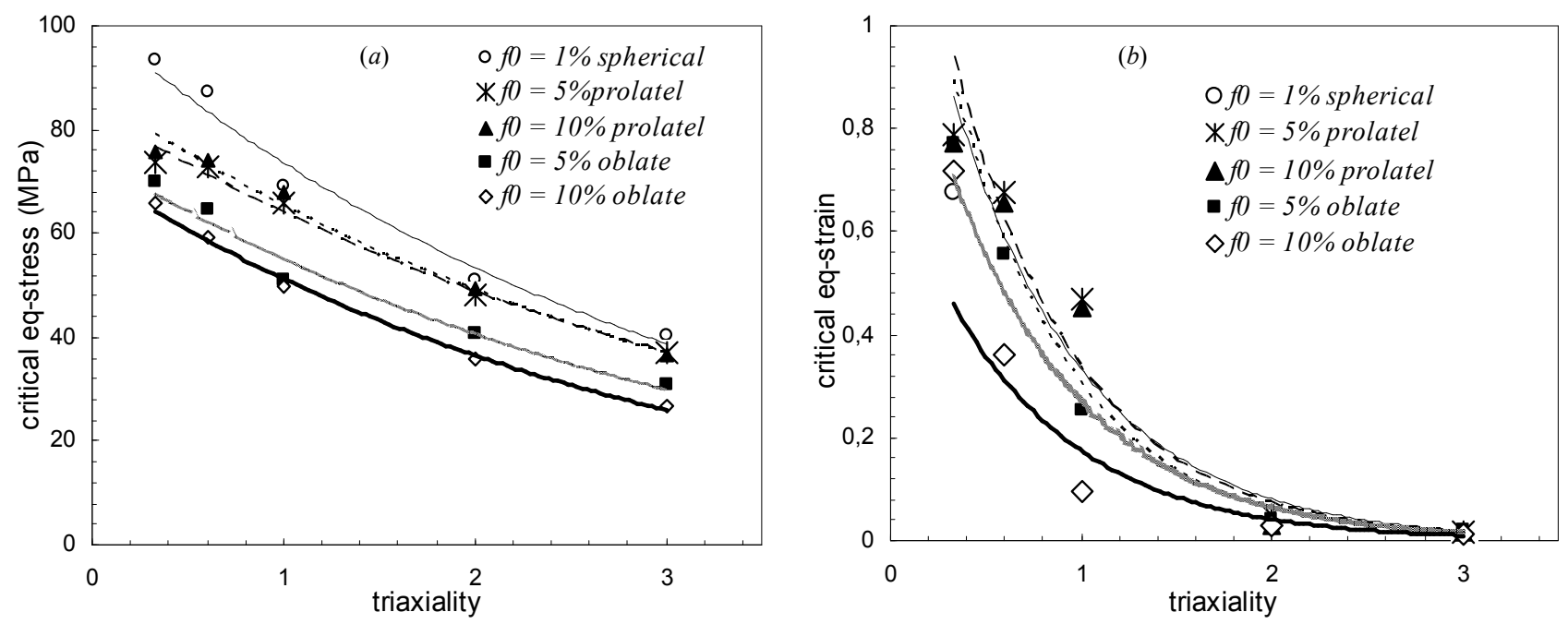

Fig. 9. Cell model results: $a$ ) critical stress versus triaxiality; $b$ ) critical strain versus triaxiality.

\section{REFERENCES}

[1] A. A. Benzerga, J. Besson, A. Pineau, "Coalescence-controlled anisotropic ductile fracture", Journal of Engineering Materials and Technology, Vol. 121, No. 2, pp. 221-229, 1999

[2] A. A. Benzerga, "Micromechanics of coalescence in ductile fracture", Journal of the Mechanics and Physics of Solids, Vol. 50, No. 6, pp. 1331-1362, 2002

[3] A. A. Benzerga, J. Besson, A. Pineau, "Anisotropic ductile fracture. Part I: experiments”, Acta Materialia, Vol. 52, No. 15, pp. 4623-4638, 2004

[4] A. A. Benzerga, J. Besson, A. Pineau, "Anisotropic ductile fracture. Part II: theory”, Acta Materialia, Vol. 52, No. 15, pp. 4639-4650, 2004

[5] A. A. Benzerga, D. Surovik, S. M. Keralavarma, "On the pathdependence of the fracture locus in ductile materials-Analysis", International Journal of Plasticity, Vol. 37, pp. 157-70, 2012

[6] X. Gao, T. Wang, J. Kim, "On ductile fracture initiation toughness: Effects of void volume fraction, void shape and void distribution", International Journal of Solids and Structures, Vol. 42, No. 18-19, pp. 5097-5117, 2005

[7] S. M. Keralavarma, A. A. Benzerga, "A constitutive model for plastically anisotropic solids with non-spherical voids", Journal of the Mechanics and Physics of Solids, Vol. 58, No. 6, pp. 874-901, 2010

[8] S. M. Keralavarma, S. Hoelscher, A. A. Benzerga, "Void growth and coalescence in anisotropic plastic solids", International Journal of Solids and Structures, Vol. 48, No. 11-12, pp. 1696-1710, 2011

[9] A. E. Huespe, A. Needleman, J. Oliver, P. J. Sánchez, "A finite thickness band method for ductile fracture analysis", International Journal of Plasticity, Vol. 25, No. 12, pp. 2349-2365, 2009

[10] A. E. Huespe, A. Needleman, J. Oliver, P. J. Sánchez, "A finite strain, finite band method for modeling ductile fracture", International Journal of Plasticity, Vol. 28, No. 1, pp. 53-69, 2012

[11] Y. Li, D. G. Karr, "Prediction of ductile fracture in tension by bifurcation, localization, and imperfection analyses", International Journal of Plasticity, Vol. 25, No. 6, pp. 1128-1153, 2009

[12] Y. Li, T. Wierzbicki, "Prediction of plane strain fracture of AHSS sheets with post-initiation softening", International Journal of Solids and Structures, Vol. 47, No. 17, pp. 2316-2327, 2010

[13] H. Li, M. W. Fu, J. Lu, H. Yang, "Ductile fracture: Experiments and computations", International Journal of Plasticity, Vol. 27, No. 2, pp. 147-180. 2011

[14] H. Stumpf, J. Makowski, K. Hackl, "Dynamical evolution of fracture process region in ductile materials", International Journal of Plasticity, Vol. 25, N o. 5, pp. 995-1010, 2009
[15] A. S. Khan, H. Liu, "A new approach for ductile fracture prediction on Al 2024-T351 alloy”, International Journal of Plasticity, Vol. 35, pp. 112,2012

[16] L. Lecarme, C. Tekoglu, T. Pardoen, "Void growth and coalescence in ductile solids with stage III and stage IV strain hardening", International Journal of Plasticity, Vol. 27, No. 8, pp. 1203-1223, 2011

[17] M. Dunand, D. Mohr, "Hybrid experimental-numerical analysis of basic ductile fracture experiments for sheet metals", International Journal of Solids and Structures, Vol. 47, No. 9, pp. 1130-1143, 2010

[18] M. Dunand, D. Mohr, "Optimized butterfly specimen for the fracture testing of sheet materials under combined normal and shear loading", Engineering Fracture Mechanics, Vol. 78, No. 17, pp. 2919-2934, 2011

[19] S. M. Graham, T. Zhang, X. Gao, M. Hayden, "Development of a combined tension-torsion experiment for calibration of ductile fracture models under conditions of low triaxiality", International Journal of Mechanical Sciences, Vol. 54, No. 1, pp. 172-181, 2012

[20] A. L. Gurson, "Continuum theory of ductile rupture by void nucleation and growth: Part-I-Yield criteria and flow rules for porous ductile media", Journal of Engineering Materials and Technology, Vol. 99, No. 1, pp. 2-15, 1977

[21] S. Yi, W. Duo, "A lower bound approach to the yield loci of porous materials", Acta Mechanica Sinica, Vol. 5, No. 3, pp. 237-243, 1989

[22] A. C. Steenbrink, E. Van der Giessen, P. D. Wu, "Void growth in glassy polymers", Journal of the Mechanics and Physics of Solids, Vol. 45, No. 3, pp. 405-437, 1997

[23] H. -Y. Jeong, "A new yield function and a hydrostatic stress-controlled void nucleation model for porous solids with pressure-sensitive matrices", International Journal of Solids and Structures, Vol. 39, No. 5, pp. 1385-1403, 2002

[24] P. J. Sànchez, A. E. Huespe, J. Oliver, "On some topics for the numerical simulation of ductile fracture", International Journal of Plasticity, Vol. 24, No. 6, pp. 1008-1038, 2008

[25] L. Cheng, T. F. Guo, "Void interaction and coalescence in polymeric materials", International Journal of Solids and Structures, Vol. 44, No. 6, pp. 1787-1808, 2007

[26] S. G. Bardenhagen, M. G. Stout, G. T. Gray, "Three-dimensional, finite deformation, viscoplastic constitutive models for polymeric materials", Mechanics of Materials, Vol. 25, No. 4, pp. 235-253, 1997

[27] T. A. Tervoort, R. J. M. Smit, W. A. M. Brekelmans, L. E. Govaert, “A constitutive equation for the elasto-viscoplastic deformation of glassy polymers", Mechanics of Time-Dependent Materials, Vol. 1, pp. 269291, 1997 
[28] J. M. Gloaguen, J. M. Lefebvre, "Plastic deformation behaviour of thermoplastic/clay nanocomposites", Polymer, Vol. 42, No. 13, pp. 5841-5847, 2001

[29] F. Zaïri, M. Naït-Abdelaziz, K. Woznica, J. M. Gloaguen, "Constitutive equations for the viscoplastic-damage behaviour of a rubber-modified polymer", European Journal of Mechanics-A/Solids, Vol. 24, No. 1, pp. $169-182,2005$

[30] F. Zaïri, B. Aour, J. M. Gloaguen, M. Naït-Abdelaziz, J. M. Lefebvre, "Numerical modeling of elastic-viscoplastic equal channel angular extrusion process of a polymer", Computational Materials Science, Vol. 38, No. 1, pp. 202-216, 2006

[31] F. Zaïri, M. Naït-Abdelaziz, K. Woznica, J. M. Gloaguen, "Elastoviscoplastic constitutive equations for the description of glassy polymers behavior at constant strain rate", Journal of Engineering Materials and Technology, Vol. 129, No. 1, pp. 29-35, 2007

[32] F. Zaïri, M. Naït-Abdelaziz, J. M. Gloaguen, J. M. Lefebvre, "Modelling of the elasto-viscoplastic damage behaviour of glassy polymers", International Journal of Plasticity, Vol. 24, No. 6, pp. 945-965, 2008

[33] F. Zaïri, M. Naït-Abdelaziz, J. M. Gloaguen, J. M. Lefebvre, “A physically-based constitutive model for anisotropic damage in rubbertoughened glassy polymers during finite deformation", International Journal of Plasticity, Vol. 27, No. 1, pp. 25-51, 2011

[34] A. D. Mulliken, M. C. Boyce, "Mechanics of the rate-dependent elasticplastic deformation of glassy polymers from low to high strain rates", International Journal of Solids and Structures, Vol. 43, No. 5, pp. 13311356, 2006

[35] J. Richeton, S. Ahzi, K. S. Vecchio, F. C. Jiang, A. Makradi, "Modeling and validation of the large deformation inelastic response of amorphous polymers over a wide range of temperatures and strain rates", International Journal of Solids and Structures, Vol. 44, No. 24, pp. 79387954, 2007

[36] M. Elmeguenni, "Effet de la triaxialité sur le comportement et la rupture du polyéthylène haute densité: approches expérimentales et numériques", Thesis, Université Lille1, 2010
[37] V. Tvergaard, "Influence of voids on shear bands instabilities under plane strain conditions", International Journal of Fracture, Vol. 17, No. 4, pp. 389-407, 1981

[38] V. Tvergaard, "On localization in ductile materials containing spherical voids", International Journal of Fracture, Vol. 18, No. 4, pp. 237-252, 1982

[39] V. Tvergaard, A. Needleman, "Analysis of the cup-cone fracture in a round tensile bar", Acta Metallurgica, Vol. 32, No. 1, pp. 157-169, 1984

[40] Z. L. Zhang, C. Thaulow, J. Ødegård, “A Complete Gurson Model Based Approach for Ductile Fracture", Engineering Fracture Mechanics, Vol. 67, No. 2, pp. 155-168, 2000

[41] J. Koplik, A. Needleman, "Void growth and coalescence in porous plastic solids", International Journal of Solids and Structures, Vol. 24 No. 8, pp. 835-853, 1988

[42] R. Becker, R. E. Smelser, O. Richmond, E. J. Appleby, "The effect of void schape on void growth and ductility in axisymmetric tension tests", Metallurgical Transactions A, Vol. 20, No. 5, pp. 853-861, 1989

[43] R. C. Lin, D. Steglich, W. Brocks, J. Betten, "Performing RVE calculations under constant stress triaxiality for monotonous and cyclic loading", International Journal for Numerical Methods in Engineering, Vol. 66, No. 8, pp. 1331-1360, 2006

[44] M. Gologanu, J. B. Leblond, G. Perrin, J. Devaux, "Theoretical models for void coalescence in porous ductile solids. II. Coalescence in columns", International Journal of Solids and Structures, Vol. 38, No. 32-33, pp. 5595-5604, 2001

[45] T. Pardoen, J. W. Hutchinson, "An extended model for void growth and coalescence", Journal of the Mechanics and Physics of Solids, Vol. 48, No. 12, pp. 2467-2512, 2000

[46] K. Siruguet, J. B. Leblond, "Effect of void locking by inclusions upon the plastic behavior of parous ductile solids-part II: theoretical modeling and numerical study of void coalescence", International Journal of Plasticity, Vol. 20, No. 2, pp. 255-268, 2004

[47] W. Brocks, D. Z. Sun, A. Hönig, "Verification of the transferability of micromechanical parameters by cell model calculations with viscoplastic materials", Vol. 11, No. 8, pp. 971-989, 1995 